\title{
Chronic arsenic poisoning from traditional Chinese medicine
}

\author{
Vincent Spilchuk MD MScCH, Aaron Thompson MD MPH
}

Cite as: CMAJ 2019 April 15;191:E424. doi: 10.1503/cmaj.181176

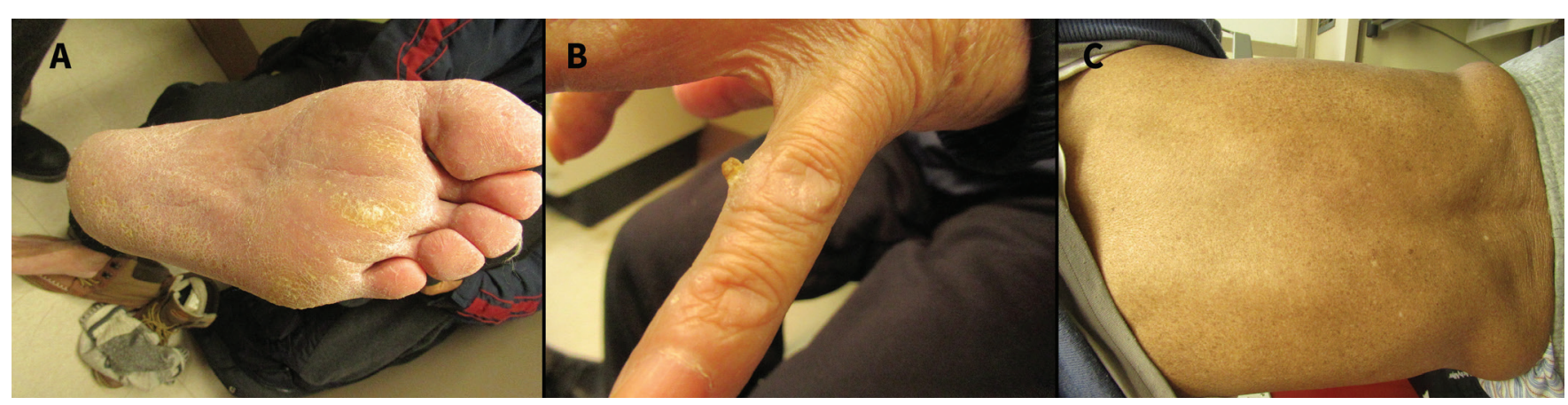

Figure 1: (A) Plantar hyperkeratosis of the left sole, (B) a hyperkeratotic lesion on the fifth digit of the left hand and (C) "raindrop" hyperpigmentation on the back of a 73-year-old man who consumed homemade traditional Chinese medicine daily for 5 years.

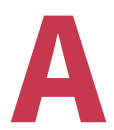

73-year-old man of Cantonese descent was referred to our department for assessment of a several-month history of worsening fatigue, weakness and numbness in his hands and feet. He reported daily consumption of homemade traditional medicinal "herbal balls" (containing up to 80 ingredients) for 5 years.

Physical examination showed hyperkeratosis on the patient's soles (Figure 1A) and palms, scattered actinic keratosis-appearing lesions over the dorsi of the hands and plantar surfaces (Figure 1B), and freckling of the trunk (Figure 1C). Neurological examination showed impaired 2-point discrimination and reduced sensory perception to monofilaments in a glove-and-stocking pattern. The patient's reported use of herbal medications prompted testing for heavy metals, including arsenic. The patient's urine level of inorganic arsenic was 1235 (normal less than 10) $\mu \mathrm{g} / \mathrm{L}$.

The cornerstone of treatment of chronic arsenic poisoning is cessation of exposure; 6 months after stopping use of the herbal medicine, the patient's arsenic level decreased to the normal range and his symptoms improved. We referred him to a dermatologist for skin cancer surveillance.

Chronic inorganic arsenic toxidrome is characterized by arsenical dermatitis (palmoplantar hyperkeratosis and hyperpigmentation), peripheral neuropathy and peripheral vascular claudication ("black foot disease"). ${ }^{1}$ Cardiovascular abnormalities, diabetes mellitus, neurotoxicity, anemia, hepatoxicity, adverse reproductive effects and nephrotoxicity have also been reported. ${ }^{1}$ Chronic exposure is a risk factor for lung, bladder and skin cancer. ${ }^{2}$ Common environmental sources of arsenic in North America include well water and traditional or herbal remedies. Speciation of urinary arsenic is required to differentiate inorganic arsenic from the comparatively benign organoarsenicals associated with seafood consumption.
Traditional Chinese medicines are recognized as potential sources of arsenic exposure and have been implicated in inadvertent arsenic toxicity. ${ }^{3}$ Analysis of samples of traditional Chinese medicines found high concentrations of arsenic at levels exceeding toxicity thresholds. ${ }^{4,5}$ Physicians should be aware that herbal and traditional remedies are commonly used and may cause arsenic toxicity.

\section{References}

1. Agency for Toxic Substances and Disease Registry (ATSDR). Toxicological profile for arsenic (update). Atlanta: U.S. Department of Health and Human Services, Public Health Service; 2007. Available: www.atsdr.cdc.gov/toxprofiles/ tp2.pdf (accessed 2017 Aug. 15).

2. IARC monographs on the evaluation of carcinogenic risks to humans, volume $100 \mathrm{C}$ arsenic and arsenic compounds. Lyon (FR): International Agency for Research on Cancer (IARC); 2012. Available: https://monographs.iarc.fr/wp-content/ uploads/2018/06/mono100C-6.pdf (accessed 2018 Jan. 8).

3. Ernst E, Thompson Coon J. Heavy metals in traditional Chinese medicines: a systematic review. Clin Pharmacol Ther 2001;70:497-504.

4. Liu L, Zhang Y, Yun Z, et al. Speciation and bioaccessibility of arsenic in traditional Chinese medicines and assessment of its potential health risk. Sci Total Environ 2018;619-620:1088-97.

5. Garvey GJ, Hahn G, Lee RV, et al. Heavy metal hazards of Asian traditional remedies. Int J Environ Health Res 2001;11:63-71.

\section{Competing interests: None declared.}

This article has been peer reviewed.

The authors have obtained patient consent.

Affiliations: Department of Occupational and Environmental Health (Spilchuk, Thompson), University of Toronto, St. Michael's Hospital; Department of Environmental and Occupational Health (Spilchuk), Public Health Ontario, Toronto, Ont.

Correspondence to: Vincent Spilchuk, v.spilchuk@mail.utoronto.ca 